\title{
A REFORMA TRABALHISTA EM FOCO: DESCONSTRUÇÃO DA PROTEÇÃO SOCIAL EM TEMPOS DE NEOLIBERALISMO AUTORITÁRIO*
}

\author{
JosÉ DARI KREIN ${ }^{1} \oplus$ \\ Ana Paula Fregnani Colombi ${ }^{1,2}$ (1)
}

\begin{abstract}
RESUMO: Este artigo analisa a reforma trabalhista e seus primeiros impactos sobre o mercado de trabalho. O objetivo foi evidenciá-la enquanto um instrumento de desconstrução de direitos, cujo caráter reitera o viés autoritário das políticas ultraneoliberais implementadas no país. Argumenta-se que a reforma trabalhista se sustenta sobre um tripéflexibilização das relaçóes de trabalho, fragilização das instituiçôes de proteção e individualização dos riscos — que condena os trabalhadores a maior vulnerabilidade social. A análise dos indicadores mostra seu fracasso mediante o aumento do desemprego e da informalidade. Defende-se, ao final, que a reforma já mostrou a que veio. Seu objetivo é disseminar a lógica da empregabilidade e do empreendedorismo em detrimento da proteção social atrelada ao assalariamento.
\end{abstract}

Palavras-chave: Reforma trabalhista. Desemprego. Flexibilização.

\section{LABOR LAW REFORM IN FOCUS: DECONSTRUCTION OF SOCIAL PROTECTION IN TIMES OF AUTHORITARIAN NEOLIBERALISM}

ABSTRACT: This paper analyzes the labor law reform and its first impacts on the labor market. The aim is to highlight it as an instrument of deconstruction of social rights whose character reiterates the authoritarian bias of the ultraneoliberal policies implemented in the country. It is argued that labor law reform is based on a tripod (flexibilization of labor relations, weakening of institutions of protection and individualization of risks) that condemns workers to greater social vulnerability. The analysis of indicators shows their failure by increasing unemployment and informality. It is argued, in the end, that the purpose of the reform is to disseminate the logic of employability and entrepreneurship to the detriment of social protection linked to wage employment.

Keywords: Labor law reform. Unemployment. Flexibilization.

\footnotetext{
*O texto faz parte da pesquisa sobre os impactos da reforma trabalhista, com financiamento do CNPq e do MPT da 15a.

${ }^{1}$ Universidade Estadual de Campinas - Campinas (SP), Brasil. E-mail: darik@unicamp.br

${ }^{2}$ Universidade Federal do Espírito Santo - Vitória (ES), Brasil. E-mail: anafcolombi@gmail.com DOI: 10.1590/ES0101-73302019223441
} 


\title{
LA REFORMA LABORAL EN FOCO: LA DECONSTRUCCIÓN DE LA PROTECCIÓN SOCIAL EN TIEMPOS DE NEOLIBERALISMO AUTORITARIO
}

\begin{abstract}
RESUMEN: El artículo analiza la reforma laboral y sus primeros impactos en el mercado laboral. El objetivo es destacarla como un instrumento de deconstrucción de derechos cuyo carácter reitera el sesgo autoritario de las políticas ultraneoliberales implementadas en el país. Se argumenta que la reforma laboral se basa en un trípode (que facilita las relaciones laborales, debilita las instituciones de protección y los riesgos de individualización) que condena a los trabajadores a una mayor vulnerabilidad social. El análisis de los indicadores muestra su fracaso con el aumento del desempleo y la informalidad. Se argumenta, al final, que la reforma ya ha demostrado de dónde vino. Su objetivo es difundir la lógica de la empleabilidad y el espíritu empresarial en detrimento de la protección social vinculada a los asalariados.
\end{abstract}

Palabras clave: Reforma laboral. Desempleo. Flexibilidad.

\section{Introdução}

\begin{abstract}
população brasileira assiste, desde 2015, à adoção de uma agenda radi$A$ calmente neoliberal que, em vez de cumprir a promessa de retomada do 11 crescimento econômico e geraçáo de emprego, vem entregando recessão econômica, desemprego e pobreza. A abertura desse novo ciclo de austeridade a partir de 2015 e o golpe parlamentar que destituiu a presidenta Dilma Rousseff representam, assim, um ponto de inflexão na trajetória política, econômica e social do país.
\end{abstract}

Desde então, o sentimento de insatisfação das classes médias e trabalhadoras vem sendo somado a um discurso reacionário de corte autoritário que combina a "intensificação de políticas neoliberais com o desejo de restaurar a ordem moral mais tradicional e a 'segurança nacional'” (LAVAL, 2018, p. 3). O alinhamento às políticas neoliberais, somado ao reacionarismo da pauta de valores, está vivificando, com a vitória de Jair Bolsonaro nas eleiçóes de 2018, um modelo à brasileira do neoliberalismo hiper-reacionário que vigora com Donald Trump nos Estados Unidos (FRASER, 2018), com o agravante periférico de subordinação aos interesses daquele país.

Nessa conjuntura de ameaça à democracia, um conjunto de alteraçóes legislativas de corte antipopular, aprovadas ou ainda em discussáo, redireciona a ação do Estado, colocando-o como guardião do mercado concorrencial (DARDOT; LAVAL, 2016) em detrimento do papel compensatório e redutor de riscos sociais que lhe fora atribuído na Constituiçẫo de 1988. Entre as medidas em 
questão, está a reforma trabalhista, que, na forma da Lei $\mathrm{n}^{\circ} 13.467 / 2017$, alterou 201 pontos da legislação trabalhista e, com a Lei no 13.429/2017, liberalizou a terceirização e ampliou o contrato temporário.

Este artigo analisa as mudanças promovidas por essa reforma e seus primeiros impactos sobre o mercado de trabalho, com o objetivo de evidenciá-la enquanto um instrumento do processo de desconstrução de direitos que vem ocorrendo no Brasil. Argumenta-se que a reforma trabalhista se sustenta sobre um tripé que promove o desmantelamento da proteção social: o aprofundamento do processo de flexibilização dos aspectos que regem a relação de emprego; a fragilização das instituiçôes públicas e da organização sindical; e a individualização do risco, condenando os trabalhadores e as trabalhadoras brasileiras à vulnerabilidade social. Assim, diante de seus primeiros impactos, defende-se que a reforma aprofunda o processo de desconstruçáo de direitos integrados à lógica da proteção social sob o acesso ao assalariamento em nome da disseminação da concorrência sob a lógica da empregabilidade e do empreendedorismo.

Para isso, o artigo divide-se em duas seçóes. A primeira analisa as mudanças na legislaçáo e o tripé sobre o qual a reforma se sustenta, evidenciando como a sua conexáo com as demais reformas, aprovadas ou ainda em discussáo, aponta para uma agenda de desmantelamento da proteção social, cujo caráter reitera o viés autoritário das políticas ultraneoliberais que vêm sendo implementadas no país. A segunda seção analisa, por meio da Pesquisa Nacional por Amostra de Domicílios Contínua (PNADC), os primeiros impactos da reforma trabalhista sobre o mercado de trabalho brasileiro. A série histórica abrange os anos de 2012 a 2018, com a finalidade de perceber se e de que forma as tendências que vinham sendo apresentadas pela dinâmica do mercado de trabalho estão sendo alteradas pelos dispositivos da nova lei.

\section{O lugar da reforma trabalhista na agenda ultraliberal}

A reforma trabalhista entrou em vigência em novembro de 2017, na forma da Lei $n^{\circ} 13.467 / 2017$ e da Lei no 13.429/2017. Ela cria uma série de regras que proporcionam maior liberdade para os empregadores ajustarem a demanda e a forma de utilizaçáo da força de trabalho de acordo com suas necessidades, em consonância com o padrão de regulação do trabalho vigente no capitalismo contemporâneo (KREIN, 2018). Cria dispositivos que retiram a proteção do trabalhador e o tornam responsável por angariar os requisitos exigidos pelo mercado e por planejar sua vida entre ocupaçóes que o remunerem em patamar suficiente para reprodução da existência em curto prazo. A ampliação da flexibilidade permitida em seus dispositivos, como se discute adiante, fomenta trajetórias profissionais móveis, que, como descreve Castel (2005), constroem carreiras em etapas escalonadas, em que "cada indivíduo deve assumir ele próprio os imprevistos de 
seu percurso profissional que se tornou descontínuo, fazer opçóes, operar a tempo de reconversóes necessárias" (CASTEL, 2005, p. 46).

A reforma é bastante ampla e baseia-se em um tripé que abrange: a ampliação de dispositivos que permitem flexibilizar a utilização do tempo de trabalho, das formas de contratação e de remuneração em favor do empregador; a fragilização das instituiçóes públicas e da organização sindical, estimulando a definição das regras de forma decentralizada e até individualizada; e a individualização dos riscos, avançando na lógica de incutir nos trabalhadores a noção de empregabilidade e responsabilização pelos riscos existentes na vida laboral. O Quadro 1 sistematiza as mudanças da lei de acordo com os objetivos nela contidos.

Com esses dispositivos, a reforma, por um lado, busca legalizar práticas de flexibilização que já estavam vigentes no mercado de trabalho brasileiro, a exemplo da terceirização, do incentivo à remuneração variável e da despadronização da jornada de trabalho. Por outro lado, ela cria uma série de regras que permitem aos empregadores ajustar com facilidade a demanda por mão de obra de acordo com a necessidade das empresas e da dinâmica do mercado, haja vista a criação de novas formas de contratação, como o trabalho intermitente.

Além disso, o ataque às organizaçóes sindicais é evidente não somente porque a reforma buscou fragilizar as fontes de financiamento dessas entidades sindicais, assim como seu poder de negociação e de organização (CASTRO, 2017; COLOMBI; LEMOS; KREIN, 2018), mas também porque alteraçóes legislativas posteriores continuam tentando minar fontes alternativas de sustentação financeira, como a contribuição negocial. Esse é o caso da Medida Provisória no 873, editada em fevereiro de 2019, que estabelece que toda forma de contribuição está condicionada à autorização prévia e voluntária do empregado e precisa ser individual, expressa e por escrito, além de tornar nula a contribuição referendada por negociação coletiva ou assembleia e obrigar os sindicatos a efetuarem o desconto via boleto bancário em vez do desconto em folha (BRASIL, 2019).

Com formas de contratação mais flexíveis, que tendem a reduzir o tempo de trabalho no emprego formal, com a despadronização da jornada de trabalho, que visa ajustar o tempo de trabalho às necessidades da empresa (DAL ROSSO, 2017; GIBB, 2017), com a maior instabilidade no patamar de remuneração e, por fim, com o ataque à capacidade de açáo coletiva, as trabalhadoras e os trabalhadores brasileiros são expostos a uma situação de maior vulnerabilidade social. Isso significa que os dispositivos mais flexíveis, aliados a uma representação sindical fragilizada, joga sobre o indivíduo a responsabilidade de entrar, manter-se e angariar renda suficiente num mercado de trabalho instável, hostil e escasso.

É a ameaça do desemprego que está no horizonte de todo assalariado em mercados de trabalho desestruturados e flexíveis, como o brasileiro, que reforça a noção de empregabilidade e o ethos do empreendedorismo, fazendo com que os 


\section{Quadro 1}

Tripé de desconstrução de direitos nos dispositivos da reforma trabalhista.

\begin{tabular}{|c|c|}
\hline Objetivo & Mudanças \\
\hline $\begin{array}{l}\text { Flexibilidade } \\
\text { das modalidades } \\
\text { de contrataçáo, } \\
\text { da jornada de } \\
\text { trabalho e da } \\
\text { remuneração }\end{array}$ & $\begin{array}{l}\text { - Liberalização da terceirização } \\
\text { - Ampliação do contrato temporário } \\
\text { - Ampliaçáo do contrato parcial } \\
\text { - Contrato intermitente } \\
\text { - Teletrabalho } \\
\text { - Estímulo à contraçáo como autônomo e pessoa jurídica } \\
\text { - Redução dos gastos com a demissáo } \\
\text { - Banco de horas } \\
\text { - Compensação individual } \\
\text { - Extensão para todos os setores da jornada } 12 x 36 \\
\text { - Redução do horário de almoço } \\
\text { - Não pagamento das horas in itinere } \\
\text { - Não pagamento de horas extras no home office } \\
\text { - Remuneração variável } \\
\text { - Redução de salários por meio de negociação coletiva } \\
\text { - Pagamento como não salário } \\
\text { - Descaracterização do salário } \\
\text { - Parcelamento dos pagamentos }\end{array}$ \\
\hline $\begin{array}{l}\text { Fragilização } \\
\text { das instituiçóes } \\
\text { públicas e da } \\
\text { organizaçáo } \\
\text { sindical }\end{array}$ & $\begin{array}{l}\text { - Prevalência do negociado sobre o legislado } \\
\text { - Negociaçáo individual sobrepóe-se à lei e aos contratos coletivos (com } \\
\text { renda superior a U\$ 3.000) } \\
\text { - Regulamentação da representação sindical do local de trabalho } \\
\text { - Fim das contribuiçóes sindicais obrigatórias e resultantes da negociação coletiva } \\
\text { - Descentralização dos espaços de definição das regras } \\
\text { - Homologação deixa de ser assistida pelo sindicato } \\
\text { - Mecanismo de soluçáo privada de conflitos } \\
\text { - Negociaçáo direta da demissão } \\
\text { - Custos das perícias judiciais ao que propóe a ação } \\
\text { - Limites ao Tribunal Superior do Trabalho (TST) para formular jurisprudências } \\
\text { - Fragilização da fiscalização }\end{array}$ \\
\hline $\begin{array}{l}\text { Individualizaçáo } \\
\text { dos riscos }\end{array}$ & $\begin{array}{l}\text { - Permissão que mulheres grávidas ou lactantes trabalhem em ambientes insalubres } \\
\text { - Formas de contratação mais precárias } \\
\text { - Instabilidade da remuneração e da jornada de trabalho } \\
\text { - Limpeza uniforme } \\
\text { - Fim do auxílio sindical na homologação } \\
\text { - Individualização da negociação } \\
\text { - Negociação direta da demissão } \\
\text { - Fragilização da fiscalização }\end{array}$ \\
\hline
\end{tabular}

Fonte: com base em Krein (2018). 
trabalhadores aceitem a flexibilidade e a autogestão como esperança de encontrar uma nova ocupação. É como se o combate à suposta rigidez do mercado de trabalho aumentasse as possibilidades de fazer parte dele, sem considerar o movimento de precarização e vulnerabilidade a que esses trabalhadores estão sendo condenados, dado o ambiente de crise do assalariamento (CASTRO, 2016) e de difusáo da chamada viração ${ }^{1}$.

Esse constante movimento de agarrar-se às oportunidades existentes, questionando cada vez menos as condiçōes de trabalho e de contratação nelas embutidas, tende a acentuar-se caso a proposta de campanha do presidente eleito seja implementada: a chamada carteira de trabalho verde e amarela ${ }^{2}$. Essa carteira substituiria a carteira de trabalho azul para os jovens ingressantes no mercado de trabalho. Nesse caso, o trabalhador negociaria individualmente todos os termos de sua contratação com o empregador.

Essa e outras reformas aprovadas ou pretendidas pelos governos ultraneoliberais contêm em si uma estratégia de desenvolvimento ancorada no dinamismo do setor privado em detrimento do papel do Estado como indutor do processo econômico e, sobretudo, como garantidor de uma tela de proteção social. Por exemplo, a Emenda Constitucional no 95 (EC 95), aprovada em 2016, estabelece um limite constitucional para o crescimento anual das despesas primárias da Uniáo, que corresponde à inflaçáo do ano anterior, com prazo de vigência de 20 anos e com a possibilidade de revisão da regra somente a partir do décimo ano. Rossi e Dweck (2016) explicam que, na prática, esse Novo Regime Fiscal implica o congelamento real das despesas totais do Governo Federal, de modo que os gastos públicos não irão acompanhar o crescimento da renda e do número de habitantes. Trata-se, esclarecem os autores, da institucionalização de uma situação de austeridade fiscal para os próximos 20 anos.

Cardoso Jr. (2016) indica que, para cumprir os limites impostos pela EC, necessariamente precisará ocorrer redução do gasto social, que compóe $65 \%$ do gasto primário federal. Como esses gastos estáo vinculados a dispositivos constitucionais que impedem seu contingenciamento, a nova regra impóe a necessidade de reformas em capítulos sociais da Constituição, atacando o processo democrático, já que um prazo de 20 anos sobrepóe-se à soberania popular manifesta nos ciclos eleitorais de quatro anos.

Isso explica o atual debate acerca de uma tentativa injusta de reforma da Previdência. Na forma da Proposta de Emenda Constitucional (PEC) 06/2019, como foi apresentada ao Brasil em fevereiro de 2019, essa reforma não visa enfrentar a precariedade do atual sistema previdenciário, mas viabilizar a redução da carga tributária, acabando com os avanços conquistados na Constituição de 1988. Prova disso é que, segundo Fagnani (apud MACHADO, 2019), cerca de $70 \%$ da economia estimada com a reforma incide sobre o Instituto Nacional do Seguro Social (INSS). A lógica é criar um sistema excludente, abrindo portas para 
o sistema de capitalização - vinculado à carteira verde e amarela $\mathrm{a}^{3}$ - que privilegia a responsabilizaçáo individual mediante a capacidade de cálculo dos cidadáos. Como argumentam Dardot e Laval (2016), trata-se de um movimento de privatização das condutas, materializado no fomento da capacidade dos sujeitos de criar as próprias condiçôes de acesso ao trabalho e ao bem-estar.

As justificativas para a implementação da reforma trabalhista e para a aprovação da reforma previdenciária concentram-se na adoção de uma nova legislação, que reestabeleceria a confiança do mercado e permitiria a retomada do crescimento econômico e da trajetória do emprego ${ }^{4}$. Entretanto, como será discutido na seçáo seguinte, o resultado de um ano e meio de implementaçáo da reforma trabalhista só mostra o seu fracasso diante das promessas de superaçáo da crise econômica e do desemprego, já que a atividade econômica segue em marcha lenta, os investimentos não reagiram e a informalidade continua em alta.

Nesse cenário, a aprovação da polêmica reforma do ensino médio (Lei no 13.415) em 2017, cuja justificativa basilar foi a preparação dos alunos para o mercado de trabalho, parece não fazer sentido, já que as oportunidades de ocupaçóes dignas, seguras e bem remuneradas se encontram cada vez mais escassas. Ferretti (2018) explica, entretanto, que as alteraçóes promovidas na Lei de Diretrizes e Bases (LDB) concentram-se na formação profissional e no desenvolvimento de competências em linha com as exigências do capitalismo contemporâneo, excluindo o papel questionador e a formaçáo integrada. Isso ocorreu tanto por meio da separação dos itinerários formativos, com a inclusão da formaçáo profissional, quanto por meio da exclusão da obrigatoriedade de disciplinas como Artes, Sociologia e Filosofia. O que se vê não é, portanto, uma contraposição, mas um alinhamento entre as reformas, já que a reforma do ensino médio "alinha-se aos postulados da Teoria do Capital Humano, bem como do individualismo meritocrático e competitivo que deriva tanto dela quanto da concepção capitalista neoliberal" (FERRETTI, 2018, p. 33).

Além disso, a reforma do ensino médio, nesses moldes, encontra sua possibilidade de efetivaçáo na reforma trabalhista, uma vez que esta possibilita a contratação de professores em modalidades mais flexíveis de trabalho. Essa necessidade tende a aumentar, já que as escolas não terão condiçóes de ofertar os cinco itinerários estabelecidos na lei, obrigando os professores a buscar novas formas de inserção dentro ou fora do campo educacional. A situação é ainda mais grave para os professores de disciplinas que tiveram sua obrigatoriedade retirada pela nova lei.

Por exemplo, no quesito trabalho temporário - uma prática que já existia nas escolas - , a reforma trabalhista permite aos estabelecimentos de ensino e aos professores celebrar contratos de trabalho por seis meses, com possibilidade de renovação, podendo incentivar modalidades de contratação por semestre. $\mathrm{O}$ próprio contrato intermitente potencializa a contrataçáo de professores para 
cursos de curta duração, da mesma forma que a liberalização da terceirização passa a permitir essa modalidade de contratação nas instituições de ensino.

Todas essas reformas estão diretamente ligadas e conformam, conjuntamente, uma mudança no projeto de desenvolvimento em consonância com as diretrizes do capitalismo contemporâneo. Enquanto a restrição dos gastos governamentais impóe cortes sociais, a reforma trabalhista potencializa o ajustamento da força de trabalho às necessidades do empregador, precarizando as relaçóes de trabalho e transferindo para os trabalhadores os riscos implícitos à sua empregabilidade. Por sua vez, a reforma do ensino médio cumpre o papel de voltar essa etapa da educação básica para a formação profissional, por meio do desenvolvimento de competências restritas que atendem às exigências do capital em detrimento da autonomia e capacidade de pensamento crítico.

Juntas, essas reformas aliam-se à proposta de reforma previdenciária, conformando um projeto neoliberal e autoritário cujo objetivo é criar o maior número possível de situaçóes de mercado: seja escolhendo os caminhos da formação e busca por competências, seja tornando-se ator de sua empregabilidade por meio de contratos de trabalho mais flexíveis e instáveis, seja elegendo a melhor forma de garantir a sobrevivência na velhice. O elemento central consiste em retirar do Estado a função de proteção social e dar a ele o papel de levar a cabo as reformas que produzam um enquadramento jurídico capaz de minar a lógica democrática da cidadania social, reforçando as desigualdades e trazendo a responsabilização sobre a vida no trabalho e fora dele para a dimensáo individual.

Nesse sentido, a implementação dessa agenda ultraliberal retrata o movimento descrito por Streeck (2013), que é a libertação da justiça de mercado da justiça social ${ }^{5}$. Em sua perspectiva, a consagração do primado duradouro do mercado sobre a política é levada a cabo por meio da ação de um Estado que garante a implementação de reformas e neutraliza as intervençóes da democracia de massas. Assim, para o autor, no capitalismo do século XXI, a questão é até que ponto os Estados conseguirão impor os direitos de propriedade e as expectativas de lucro dos mercados resguardando alguma legitimidade democrática, já que sua capacidade de fazer mediações entre direitos sociais e requisitos de acumulação de capital está afetada. Para Prado (2018), uma agenda dessa natureza e profundidade em termos de retirada de direitos promove um esvaziamento da substância da democracia, pois democracia pressupóe cidadania, ao passo que o neoliberalismo quer transformar o ser humano em mero agente econômico, gerando menos civilização e mais barbárie:

As reformas capitalistas propostas e implementadas pelo neoliberalismo têm, pois, sua lógica: elas visam, em última análise, recuperar a taxa de lucro e, assim, a acumulaçáo, viabilizando a continuidade do capitalismo. Portanto, elas podem elevar um pouco a taxa de crescimento econômico, mas ao fazê-lo, elas incrementarão 
também a taxa de exploração vigente na economia capitalista no Brasil. Produzirão, também, uma piora na distribuição da renda familiar, assim como uma reduçáo dos gastos sociais do Estado. Ao procurar regular o sistema econômico por meio da imposição generalizada da racionalidade competitiva, não apenas entre as empresas, mas também entre os indivíduos em geral tomados como empresas de si mesmos, tencionará a sociedade de tal modo que, ao fim e ao cabo, ter-se-á não mais civilização, mas mais barbárie (PRADO, 2018, p. 135).

É isso que está em jogo na face autoritária do projeto ultraneoliberal cuja implementação avança no Brasil, tendo na reforma trabalhista uma ferramenta de disseminação de uma nova forma de relacionar-se com o trabalho, baseada na lógica da empregabilidade e do empreendedorismo. Nessa direção, a nova onda de austeridade que vem ocorrendo nos últimos cinco anos no Brasil representa o esgotamento do processo de mediação entre os direitos dos cidadãos e os requisitos de acumulação do capital que os governos petistas realizaram, dando espaço à desconstruçâo de direitos sociais e à piora nas condiçóes de vida dos trabalhadores brasileiros, como já se pode ver nos primeiros impactos da reforma trabalhista.

\section{Os primeiros impactos da reforma trabalhista}

A adoção de uma agenda ultraneoliberal vem aglutinando forças políticas desde o golpe parlamentar de 2016. Ela foi fundamentada no documento do Partido do Movimento Democrático Brasileiro (PMDB) denominado de Uma Ponte para o Futuro (FUNDAÇÃO ULYSSES GUIMARÃES; PMDB, 2015), que realiza um diagnóstico dos problemas do país tendo como referência não a construção da nação, mas a viabilização dos negócios privados, especialmente os vinculados ao sistema financeiro. Portanto, a reforma trabalhista visa adquirir a confiança do mercado como soluçáo para o país voltar a crescer e, consequentemente, gerar emprego, porém os primeiros impactos dessa reforma evidenciam que os resultados estão longe do esperado.

A recuperação econômica não aconteceu até o momento, o que coloca em xeque a teoria do ajuste fiscal expansionista, segundo a qual um ajuste fiscal não contrai a demanda agregada, mas melhora as condiçóes de confiança do setor privado, resultando em efeito expansionista sobre a renda e o emprego (GIAVAZZI; PAGANO, 1990). Depois de enfrentar dois anos de recessáo, 2017 e 2018, a economia brasileira voltou a crescer timidamente. Em termos reais, isso corresponde a um crescimento de 1,0 e $1,1 \%$ ao ano, respectivamente. É um crescimento pífio depois de uma queda de 6,9\% no acumulado do biênio 2015-2016. É a mais lenta recuperação da economia nas crises vivenciadas pelo país desde os anos 1930. 
Em 2017, o crescimento somente náo foi negativo por conta do desempenho do setor agrícola e do consumo das famílias, ambos atrelados a fatores extraordinários, quais sejam, a supersafra e a liberação do FGTS, respectivamente. Em 2018, a economia continuou no mesmo patamar, e, em 2019, as expectativas apontam para a manutenção desse cenário. Os dados do baixo dinamismo são retroalimentados pelos seus efeitos negativos sobre o mercado de trabalho, pois o baixo crescimento não gera emprego e renda, movimentos que, por sua vez, afetam negativamente a demanda interna, tanto pela queda da renda quanto pelo acesso ao crédito. Esse processo constitui um círculo vicioso, em que a ausência de recuperação da economia é reforçada pela desestruturação do mercado de trabalho.

O resultado é uma nítida sensação de piora nas condiçóes de vida daqueles que vivem do próprio trabalho. Esse aspecto é confirmado por uma explosão na taxa de desocupação e no desemprego aberto ${ }^{6}$ a partir de 2014 , conforme dados da PNADC. O grande salto desses indicadores negativos ocorreu em 2016, como consequência da forte queda do produto interno bruto (PIB) naquele ano e no anterior. A aprovação das reformas não alterou a trajetória do crescimento econômico, tampouco a trajetória do desemprego, como se pode ver no Gráfico 1.

A pequena queda na taxa de desemprego ao longo de 2017 se deu à custa do aumento do emprego informal, do trabalho por conta própria e da subo-

\section{Gráfico 1}

Crescimento econômico, taxa de desocupação e população desocupada.

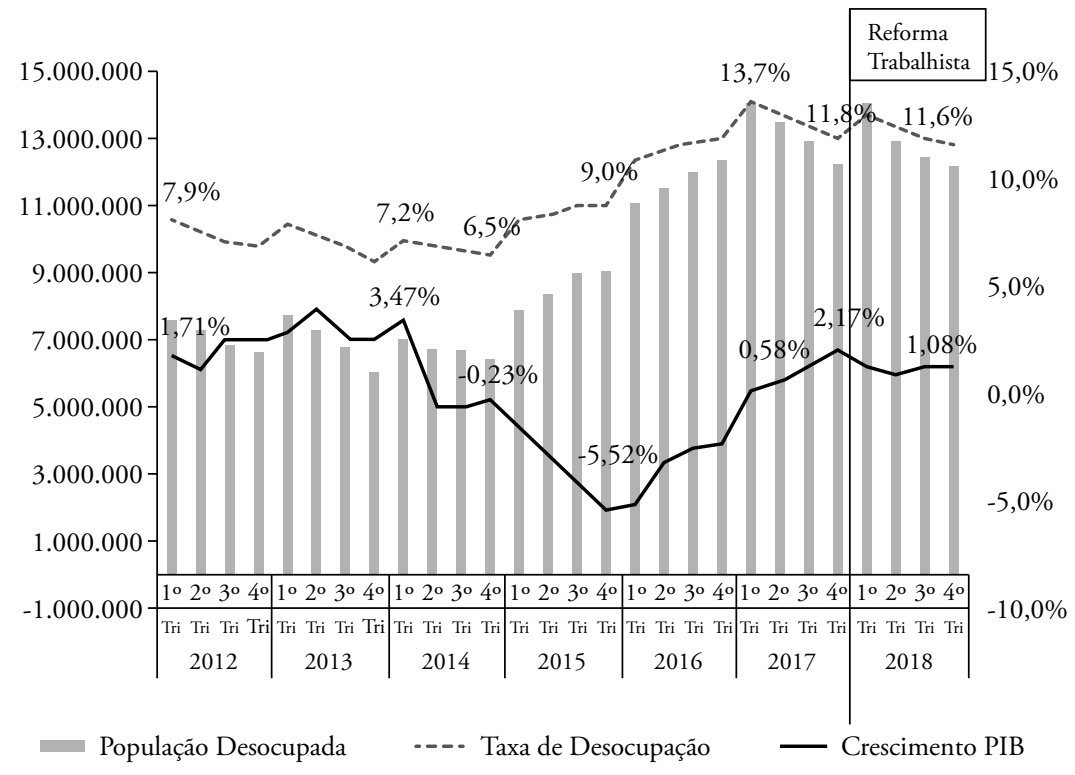

Fonte: com base em Microdados PNADCT (IBGE). 
cupação. Considerando que o trabalho informal inclui os empregados sem carteira de trabalho, os trabalhadores domésticos sem carteira, os trabalhadores familiares auxiliares e os trabalhadores por conta própria, o Gráfico 2 mostra que, a partir do terceiro trimestre de 2014, o curso da formalidade caiu e o da informalização subiu, inclusive seguindo a mesma tendência que já vinha se desenhando antes da implementação da reforma trabalhista. Em 2018, os que se encontravam na informalidade superaram os formalizados novamente, em termos absolutos e relativos. A informalidade tem crescido não somente entre as atividades de serviços, em que já era mais presente, mas também entre os setores historicamente reconhecidos por maior incidência de trabalho formal e melhor estruturação. Esse é o caso do setor industrial, que apresentou, segundo a PNADC, um aumento de 5,6\% de trabalhadores informais entre o último trimestre de 2012 e o mesmo período de 2018. É importante destacar, também, que no mesmo período a informalidade cresceu mais entre os trabalhadores com nível superior (incompleto e completo).

A expressão de uma piora no mercado de trabalho também apareceu no comportamento da taxa de subutilização da força de trabalho, como se vê no Gráfico 3, que engloba não somente o desemprego aberto, mas também aqueles que, embora tenham ocupação, gostariam de trabalhar mais horas, mas não conseguem (subocupados). A subocupação cresceu de 4,8 para $7,4 \%$ entre 2014 e 2018, comparando o terceiro trimestre de cada ano. Para exemplificar a pre-

\section{Gráfico 2}

Taxa de formalidade $\mathrm{x}$ informalidade.

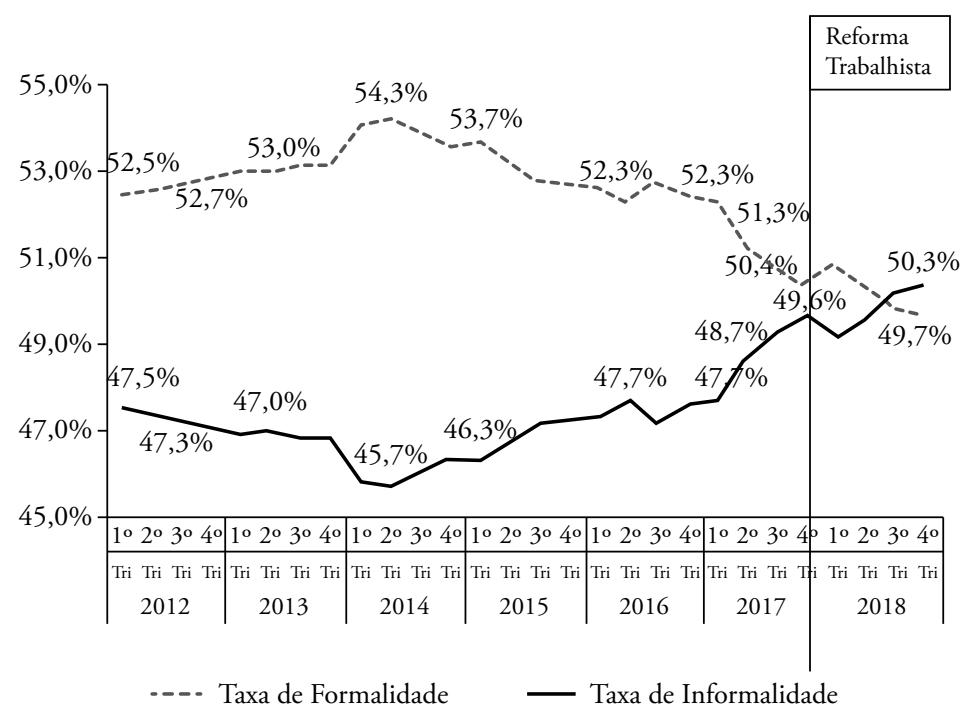

Fonte: com base em Microdados PNADCT (IBGE). 
cariedade, os subocupados trabalham em média 19 horas semanais e têm renda média mensal de $\mathrm{R} \$ 734$, enquanto a jornada média dos ocupados é de 38 horas semanais, com renda média de $\mathrm{R} \$ 2.187^{7}$. Ou seja, os subocupados trabalham em média metade das horas e recebem um terço dos rendimentos do trabalho do total dos ocupados. Somando o total de trabalhadores subocupados, desocupados e de força de trabalho potencial ${ }^{8}$, chega-se a um nível de subutilização da força de trabalho que atinge um contingente de mais de 27 milhóes de pessoas, considerando o terceiro trimestre de 2018.

Como mostram os indicadores, nem o ajuste fiscal permanente reverteu a expectativa de investimento do setor privado com impactos significativos sobre o crescimento do PIB, tampouco a reforma trabalhista conseguiu conter o desemprego e o movimento de crescimento da informalidade que reapareceram em 2015. Com o aumento da informalidade (que atingiu 39,4 milhóes de ocupados no terceiro trimestre de 2018) e o incremento de atividades com remuneraçáo mais baixa (trabalhadores por conta própria e subocupados), o processo de desestruturação do mercado de trabalho corroborou a destruição das fontes de financiamento da seguridade social, tornando o deficit da previdência não uma realidade, mas uma profecia autorrealizável. Além disso, dados do Cadastro Geral de Empregados e Desempregados (CAGED) (BRASIL, 2016b) mostram aumento do número de empregos tipicamente terceirizáveis. Também houve incre-

\section{Gráfico 3}

Subutilização da força de trabalho.

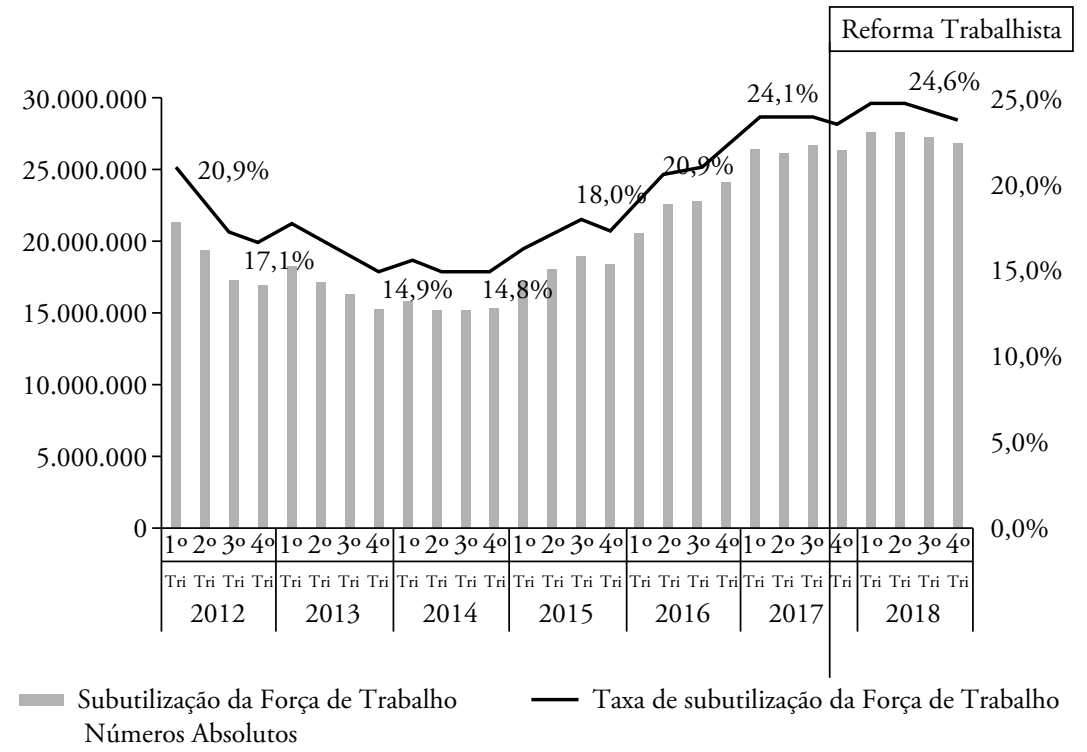

Fonte: com base em Microdados PNADCT (IBGE). 
mento nas ocupações dos autônomos, como estratégia de sobrevivência, dentre as quais se destacam vendedores indefinidos, vendedores a domicílio, vendedores de quiosques e motoristas autônomos. Os contratos intermitentes e parciais, por sua vez, ainda têm baixa incidência: não passam de $1 \%$ dos empregos formais, conforme os dados da Relação Anual de Informaçôes Sociais (RAIS).

Em suma, os dados mostram que, após a reforma, a geração de ocupaçôes ficou concentrada em atividades mais precárias, com crescimento da informalidade, da subocupação e das atividades tipicamente terceirizáveis. Isso indica, por um lado, que o baixo crescimento econômico é variável-chave para a geraçáo de empregos. Sem ele, a mudança da legislação não tem força para potencializar a dinâmica do mercado de trabalho. Por outro lado, a reforma em si só tem mostrado seu potencial de rebaixamento do marco legal com a introdução de contratos atípicos e precários, o que pode se disseminar com maior ou menor intensidade, a depender do ritmo de crescimento. Assim, as evidências são de continuidade das tendências iniciadas com a crise de 2015, sem que agenda ultraneoliberal tenha sido capaz de reverter a dinâmica econômica, a geração de emprego e a tendência de incremento da informalidade, o que reforça o movimento de destruição de direitos e do assalariamento como canais de acesso à cidadania social.

\section{Considerações finais}

Este artigo examinou as mudanças introduzidas pela reforma trabalhista, mostrando que seus dispositivos visam flexibilizar a utilização do tempo de trabalho, as formas de contratação e de remuneração, além de fragilizar as instituiçôes de proteção e individualizar os riscos, submetendo os trabalhadores a trajetórias profissionais cada vez mais instáveis e inseguras. Ao dificultar o acesso ao assalariamento seguro, a reforma trabalhista configura-se como um instrumento de desconstrução dos direitos sociais.

Ela não cumpre esse papel de maneira isolada, mas em consonância com as demais reformas em discussão ou já aprovadas. Todas elas surgem, a cada momento, como decisivas para enfrentar os problemas brasileiros. A emenda do teto dos gastos foi apresentada como fundamental para realizar o ajuste fiscal, com a promessa de retomar o crescimento econômico, o que náo ocorreu. Depois, foi vendida a tese de que a reforma trabalhista geraria emprego e formalização dos contratos, o que também não está acontecendo. A reforma do ensino médio representou uma condição para a entrada dos jovens mais bem preparados num mercado de trabalho que, nas condiçóes atuais, não oferece lugar para eles. Agora, prega-se que a reforma da Previdência é a salvação dos problemas econômicos nacionais. Mas o que está em jogo é a preocupação do mercado financeiro em viabilizar recursos para garantir a sua rentabilidade nas aplicaçôes da dívida pública, mesmo que isso signifique dilapidar o patrimônio público e privar as pessoas 
do acesso ao atendimento de suas necessidades básicas. Dessa forma, as políticas que prejudicam os mais pobres são apresentadas como redentoras do país, sem que haja espaço para oposiçóes.

A trajetória de baixo crescimento desde 2015 tem se mostrado decisiva para a manutençấo do desemprego e a escalada da informalidade e da subocupaçáo. A reforma trabalhista, propagada como instrumento capaz de reverter esse quadro, não tem conseguido alterar a tendência de nenhum desses indicadores. Pelo contrário, ela tem se mostrado um canal de aprofundamento da exploraçáo dos trabalhadores, pelo seu potencial de criar ocupaçôes precárias em qualquer conjuntura econômica. Isso significa que, nas condiçóes de uma economia dependente e em processo de desindustrialização, qualquer patamar de crescimento econômico encontra na nova legislação trabalhista a potência para a criação de ocupaçóes mais precárias.

A natureza da nova legislaçáo trabalhista e o seu potencial de desconstrução de direitos ao lado das demais reformas evidenciam, portanto, a degradaçáo do papel protetor do Estado e o comprometimento das possibilidades de implementação de qualquer projeto de desenvolvimento baseado na justiça social. Do ponto de vista do trabalho, o que vem se concretizando diante da crise do assalariamento é, como diria Castel (2005), a instauração de uma mobilidade generalizada das relaçóes de trabalho, das carreiras profissionais e das proteçóes ligadas ao estatuto do emprego. A perversidade desse processo é acentuada em países da periferia do capitalismo, como o Brasil. Se durante o desenvolvimento capitalista deste país a cidadania configurou-se como um sistema fluido, cuja porta de entrada se abre e se fecha, inclui e exclui os indivíduos, gerando um mundo de direitos de curta duração (CARDOSO, 2016), de agora em diante o que parece estar em foco não é mais a expectativa de inclusão cidadá, mas a necessidade de buscar as condições individuais para permanecer no jogo da concorrência.

\section{Notas}

1. "A trajetória profissional dos motoboys entrevistados deixa isso evidente. Hoje motoboy-celetista e entregador de pizza, amanhã motofretista-MEI, ontem montador em fábrica de sapatos, manobrista, pizzaiolo, feirante, funileiro, funcionário de lava-rápido. Motogirl hoje, antes diarista, copeira, coordenadora de clínica para viciados em drogas. Motofretista, serralheiro, repositor de mercadorias; confeiteiro e também ajudante de pedreiro. Proprietário de loja de bebidas, trabalhador na roça, funcionário do Banco do Brasil e hoje motofretista autônomo. Motoboy hoje, antes faxineiro, porteiro e cobrador de ônibus. Este é o movimento com que grande parte dos brasileiros tecem o mundo do trabalho" (ABÍLIO, 2017).

2. Para uma discussão crítica a respeito, ver Galvão (2018). 
3. "Se você quiser escolher os direitos atuais, você entra no sistema atual. Se quiser optar pelo sistema novo, vai para a carteira verde e amarela, é um sistema de capitalização, os encargos são diferentes, as empresas não têm o custo sobre a folha de pagamento, vamos financiar esse sistema de uma outra forma”. Essa é uma fala do Ministro da Economia, Paulo Guedes, mostrando que o trabalhador que optar pelo regime de trabalho com direitos flexíveis entra, automaticamente, no sistema de capitalização. Disponível em: <https://www1.folha.uol.com.br/mercado/2019/02/carteira-verde-e-amarela-vira-depois-da-reforma-da-previdencia-indica-guedes.shtml>. Acesso em: 20 mar. 2019.

4. "O governo federal acredita que a nova lei trabalhista, que começa a vigorar em 11 de novembro, vai tornar viável a geração de mais de seis milhóes de empregos no Brasil, afirmou o ministro da Fazenda, Henrique Meirelles, durante entrevista à EBC nesta segunda-feira (30)" (MARTELLO, 2017).

5. A justiça de mercado é a distribuição do resultado da produção de acordo com a avaliação pelo mercado dos desempenhos individuais dos envolvidos, expressa por meio dos seus preços relativos. A justiça social, pelo contrário, rege-se por normas culturais e baseia-se no direito estatutário, não no direito contratual. Rege-se por concepçôes coletivas de honestidade, equidade e reciprocidade, concede direitos a um nível mínimo de vida, independentemente do desempenho econômico e da capacidade de desempenho, e reconhece direitos civis e humanos, tais como o direito à saúde, à segurança social, à participação na vida da comunidade, à proteçấo do emprego, à organização sindical etc. (STREECK, 2013, p. 99).

6. A taxa engloba as pessoas que estão procurando trabalho e estão sem nenhuma ocupação.

7. Em valores de novembro de 2018.

8. Isso quer dizer: somadas as pessoas que trabalhavam menos de 40 horas semanais e gostariam de trabalhar mais, as pessoas desocupadas que procuraram ocupação nos últimos 30 dias e estavam aptas a começar uma ocupaçáo imediatamente e as pessoas fora da força de trabalho, que gostariam de trabalhar e que não procuraram ocupação nos últimos 30 dias ou não estavam disponíveis para trabalhar no momento da pesquisa.

\section{Referências}

ABÍLIO, L. C. Uberização do trabalho: subsunção real da viração. Passa Palavra, 19 fev. 2017. Disponível em: <http://passapalavra.info/2017/02/110685>. Acesso em: 17 jul. 2017.

BRASIL. Emenda Constitucional 95, de 15 de dezembro de 2016. Altera o Ato das Disposiçóes Constitucionais Transitórias, para instituir o Novo Regime Fiscal, e dá outras providências. Brasil, 2016a. Disponível em: <http://www.planalto.gov.br/ccivil 03/ Constituicao/Emendas/Emc/emc95.htm>. Acesso em: 21 jul. 2017.

BRASIL. Lei no 13.415/2017, de 16 de fevereiro de 2017. Altera as Leis no 9.394, de 20 de dezembro de 1996, que estabelece as diretrizes e bases da educação nacional, e no 11.494 , de 20 de junho 2007, que regulamenta o Fundo de Manutenção e Desenvolvimento da Educação Básica e de Valorização dos Profissionais da Educação, a Consolidação das Leis do Trabalho - CLT, aprovada pelo Decreto-Lei no 5.452 , de $1^{\circ}$ de maio de 1943 , e o Decreto-Lei no 236, de 28 de fevereiro de 1967; revoga a Lei no 11.161, de 5 de agosto de 
2005; e institui a Política de Fomento à Implementação de Escolas de Ensino Médio em Tempo Integral. Brasil, 2017a. Disponível em: <http://www.planalto.gov.br/ccivil 03/ Ato2015-2018/2017/Lei/L13415.htm>. Acesso em: 20 jul. 2017.

BRASIL. Lei no 13.429/2017, de 31 de março de 2017. Altera dispositivos da Lei no 6.019, de 3 de janeiro de 1974, que dispóe sobre o trabalho temporário nas empresas urbanas e dá outras providências; e dispóe sobre as relaçóes de trabalho na empresa de prestação de serviços a terceiros. Brasil, 2017b. Disponível em: <http://www.planalto.gov. br/ccivil 03/ Ato2015-2018/2017/Lei/L13429.htm>. Acesso em: 1o jul. 2017.

BRASIL. Lei no 13.467/2017, de 13 de julho de 2017. Altera a Consolidação das Leis do Trabalho (CLT), aprovada pelo Decreto-Lei $\mathrm{n}^{\circ} 5.452$, de $1^{\circ}$ de maio de 1943 , e as Leis no 6.019, de 3 de janeiro de 1974, 8.036, de 11 de maio de 1990, e 8.212, de 24 de julho de 1991, a fim de adequar a legislação às novas relaçóes de trabalho. Brasil, 2017c. Disponível em: <http://www.planalto.gov.br/ccivil 03/ ato2015-2018/2017/lei/113467. $\underline{\mathrm{htm}}>$. Acesso em: 11 set. 2017.

BRASIL. Medida Provisória no 873, de $1^{\circ}$ de março de 2019. Diário Oficial da Uniáo, Brasília, Seção 1, p. 1, $1^{\circ}$ mar. 2019. Disponível em: <http://www.planalto.gov.br/ ccivil 03/ Ato2019-2022/2019/Mpv/mpv873.htm>. Acesso em: 5 mar. 2019.

BRASIL. Ministério do Trabalho. Cadastro Geral de Empregados e Desempregados (Caged). Brasília: Ministério do Trabalho, 2016b. Disponível em: <http://portalfat.mte. gov.br/programas-e-acoes-2/caged-3/>. Acesso em: 11 jan. 2019.

CARDOSO, A. M. Work in Brazil: essays in historical and economic sociology. Rio de Janeiro: Editora da Universidade do Estado do Rio de Janeiro, 2016.

CARDOSO JR., J. C. Uma análise técnica das justificativas da PEC no 241/2016. 2016. Disponível em: <http://plataformapoliticasocial.com.br/wp-content/uploads/2016/10/Asjustifica\%C3\%A7\%C3\%B5es-da-PEC-241-2016-10-12.pdf>. Acesso em: 12 jan. 2019.

CASTEL, R. A insegurança social: o que é ser protegido? Petrópolis: Vozes, 2005.

CASTRO, B. G. de. As armadilhas da flexibilidade: trabalho e gênero no setor de tecnologia da informação. São Paulo: Annablume, 2016.

CASTRO, M. S. P. de. Impactos da Reforma Trabalhista sobre a organização sindical e a negociação coletiva. Perspectivas, n. 13/2017.

COLOMBI, A. P. F.; LEMOS, P. R.; KREIN, J. D. Entre negociação e mobilização: as estratégias da CUT e da FS frente à reforma trabalhista no Brasil. Revista Brasileira de Estudos do Trabalho, v. 17, n. 2, jul-dez. 2018. http://doi.org/10.22478/ufpb.1676$\underline{4439.2018 \mathrm{v} 17 \mathrm{n} 2.44618}$

DAL ROSSO, S. O ardil da flexibilidade: os trabalhadores e a teoria do valor. São Paulo: Boitempo, 2017.

DARDOT, P.; LAVAL, C. A nova razáo do mundo. São Paulo: Boitempo, 2016.

FERRETTI, C. J. A reforma do Ensino Médio e sua questionável concepção de qualidade da educação. Estudos Avançados, São Paulo, v. 32, n. 93, 2018. http://dx.doi. org/10.5935/0103-4014.20180028 
FRASER, N. Do neoliberalismo progressista a Trump - e além. Política \& Sociedade, Florianópolis, v. 17, n. 40, 2018. https://doi.org/10.5007/2175-7984.2018v17n40p43

FUNDAÇÃO ULYSSES GUIMARÃES; PARTIDO DO MOVIMENTO DEMOCRÁTICO BRASILEIRO (PMDB). Uma ponte para o futuro. Brasília: Fundação Ulisses Guimarães, 2015. Disponível em: <https://www.fundacaoulysses.org.br/wp-content/ uploads/2016/11/UMA-PONTE-PARA-O-FUTURO.pdf>. Acesso em: 3 mar. 2016.

GALVÃO, A. Bolsonaro e a pá de cal nos direitos dos trabalhadores. Carta Capital, 23 out. 2018. Disponível em: <https://www.cartacapital.com.br/blogs/brasil-debate/bolsonaro-ea-pa-de-cal-nos-direitos-dos-trabalhadores-brasileiros>. Acesso em: 29 out. 2018.

GIAVAZZI, F; PAGANO, M. Can severe fiscal contractions be expansionary? Tales of two small European countries. NBER Working Paper, Cambridge, n. 3372, 1990. https://doi.org/10.3386/w3372

GIBB, L. S. F. A tendência de despadronizaçáo da jornada de trabalho. Tese (Doutorado em Desenvolvimento Econômico) - Instituto de Economia, Universidade Estadual de Campinas, Campinas, 2017.

INSTITUTO BRASILEIRO DE GEOGRAFIA E ESTATÍSTICA (IBGE). Pesquisa Nacional por Amostras de Domicílios Contínua (PNAD Contínua). Rio de Janeiro: IBGE. Disponível em: <https://www.ibge.gov.br/estatisticas/sociais/trabalho/17270pnad-continua.html?=\&t=o-que-e $>$. Acesso em: 11 jan. 2019.

KREIN, J. D. O desmonte dos direitos, as novas configuraçôes do trabalho e o esvaziamento da ação coletiva. Tempo Social, São Paulo, v. 30, n. 1, 2018.

LAVAL, C. Bolsonaro e o momento hiperautoritário do neoliberalismo. Blog da Boitempo, São Paulo, 29 out. 2018. Disponível em: <https://blogdaboitempo.com.br/2018/10/29/ o-momento-hiperautoritario-do-neoliberalismo/>. Acesso em: 20 fev. 2019.

MACHADO, R. Da seguridade social ao seguro social. Reforma previdenciária pretende sepultar o pacto de 1988. Entrevista especial com Eduardo Fagnani. São Leopoldo, 26 fev. 2019. Disponível em: <http://www.ihu.unisinos.br/159-noticias/ entrevistas/586966-da-seguridade-social-ao-seguro-social-reforma-previdenciariapretende-sepultar-o-pacto-de-1988-entrevista-especial-com-eduardo-fagnani>. Acesso em: $1^{\circ}$ abr. 2019.

MARTELLO, A. Nova lei trabalhista deve gerar mais de 6 milhóes de empregos, diz Meirelles. G1, Brasília, 30 out. 2017. Seção de Economia. Disponível em: <https:// g1.globo.com/economia/noticia/nova-lei-trabalhista-vai-gerar-mais-de-6-milhoes-deempregos-diz-meirelles.ghtml>. Acesso em: 30 out. 2017.

PRADO, E. Ciência da Economia: demarcações. Curitiba: CRV, 2018.

ROSSI, P.; DWECK, E. Impactos do novo regime fiscal na saúde e na educação. Cadernos de Saúde Pública, v. 32, n. 12, 2016. http://dx.doi.org/10.1590/0102-311x00194316

STREECK, W. Tempo comprado: a crise adiada do capitalismo democrático. Lisboa: Actual, 2013. 


\section{SOBRE OS AUTORES}

José Dari Krein é docente da Universidade Estadual de Campinas, possui doutorado em Economia Social e do Trabalho pela Universidade Estadual de Campinas (2007). Tem experiência na área de Economia, com ênfase em Emprego, Relações de Trabalho, Sindicalismo e Negociação Coletiva. Professor do Instituto de Economia da Unicamp, Pesquisador do Centro de Estudos Sindicais e Economia do Trabalho (CESIT). Linhas de pesquisa: mercado e relaçóes de trabalho, sindicalismo.

Ana Paula Fregnani Colombi é professora do Departamento de Economia da Universidade Federal do Espírito Santo (UFES), possui doutorado em Economia Social e do Trabalho pela Universidade Estadual de Campinas (2018). Tem experiência na área de Economia, com ênfase em desenvolvimento econômico, economia do trabalho, mercado e relaçóes de trabalho e sindicalismo. Linhas de pesquisa: mercado e relaçóes de trabalho, sindicalismo.

Recebido em 3 de maio de 2019.

Aceito em 25 de setembro de 2019. 